\title{
The Relationship between A utomatic Negative Thoughts and D epression among a Sample of University of Nizwa Students
}

\author{
Basim Mohammad Aldahadha* \& Suad Mohamed Sulaiman \\ University of Nizwa, Sultanate of Oman, Sultan Qaboos University, Sultanate of Oman
}

Submitted: $7 \backslash 6 \backslash 2011$

Revised: $1 \backslash 12 \backslash 2011$

Accepted: $4 \backslash 1 \backslash 2012$

The purpose of this study was to investigate the relationship between the automatic thoughts and depression in light of gender, specialization, level of study, achievement and hours of internet-usage. The sample of this study consisted of 329 (101 males and 228 females). Two instruments were used to collect the data: the Automatic Thought Questionnaire (ATQ) and the Beck Depression Inventory- second edition. (BDI-II). The results showed a positive correlation between depression and ATQ $(r=0.8, p .<0.001)$. There was a negative correlation between ATQ and depression among non-depressed students $(r=-0.78, p<0.001)$. There were significant differences between male and female students $(p<0.05)$ in favor of females in ATQ. There were significant differences between the levels of achievement in favor of students with excellent GPA. The results also showed that there were no significant differences ( $p$ 0.05) that related to other variables.

Keywords: A utomatic thoughts questionnaire, Depression, Gender, Achievements.

$$
\text { العلاقة بين الأفكار الآلية السلبية والاكتئاب لدى عينة من طلبة جامعة نزوى }
$$

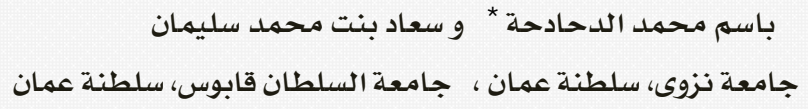

* dahadha2004@yahoo.com 


\section{INTRODUCTION}

In cognitive theories of psychopathology, it is assumed that negative automatic cognitions play a central role in the development and maintenance of emotional disorders (Beck, 1996). Different self-report questionnaires have been developed to assess negative cognitions such as Automatic Thoughts Questionnaire, a Cognition Checklist, modified Catastrophic Cognitions Questionnaire and the Anxious Self-statements Questionnaire. The Automatic Thoughts Questionnaire is the most useful and best validated instrument for measuring negative self-referent cognitions (Boelen, 2007; HolIon and Kendall, 1980).

As noted by Ingram and Wisnicki (1988) the development of the ATQ has facilitated our knowledge of negative cognitive processes in psychopathology, and the function of cognitive change mechanisms.

According to the cognitive model of de pression, functionally disordered cognition plays an important role in the emergence and perpetuation of depression (Dowd, 2003). Activation of functionally disordered cognition in individuals prone to depression facilitates "automatic" emergence of negative thoughts, these negative automatic thoughts reinforce and nourish underlying beliefs and presumptions that are depressive in origin, and as the negative automatic thoughts intensify depression becomes more severe. Levels of depression are parallel to the cognitive distortions experienced by patients with chronic pain (Clark, and Watson, 1991; Dobson and Show, 1986; Yucel, Kora, Ozyalcin, Alcalar, \& Ozdemir, 2002).

\section{Review of literature}

Numerous of previous studies have supported the relationship between ATQ and depression. These scores were able to differentiate between depressed and non -depressed groups, as well as their internal consistency and concurrent validity (Clark, 1988; Glass and Arnkoff, 1997; Harrell and Ryon, 1983; Hill, Oei, and Hill 1989; Hollon, Kendall, and Lumry, 1986). Given our focus on reducing the scale to a single substantive factor, our review concentrated on studies that had a relationship between automatic thoughts and depression, in light of some variables.
Deardorff, Mcintosh, Adamek, Bier and Saalfeld (1985) used 144 factory workers to explore the factorial validity of ATQ scores. Via principal components, they found three factors that accounted for $49.5 \%$ of the scale variance. However, the first component accounted for $39.6 \%$, whereas the second and third components accounted for $5.3 \%$ and $4.6 \%$ of the variance. Only 7 of the items are salient at or above .50 were the same as those identified by Hollon and Kendall (1980) and several of the items were substantially corre lated with other components.

Furthermore, Deardorff, Mcintosh, Adamek, Bier, \& Saalfeld (1985) reported item-tototal correlations ranging from 0.43 to 0.81 and coefficient alpha and split-half reliabilities of .92 and .95, respectively. Similar results were found by Charles, Mollard, and Cottraux (1989). However, within a French sample, they found only one interpretable factor underlying the 30 items (i.e., negative self-concept), and their data yielded a coefficient alpha of .93. On the other hand, Deardorff and colleagues (1985) and Charles et al. (1989) studies suggested that one factor underlies the ATQ.

Kazdin (1990) examined the ATQ with 250 children. He extracted three factors and re ported items that were salient at or above .50 on these three factors. Although $56.3 \%$ of scale variance was accounted for by these three factors, the first factor accounted for a large proportion of the variance. Also, there was a large drop between the first and second values (14.37 to 1.40), and all but one item was corre lated at or above 0.30 with the first factor. Internal consistency estimates based on Kazdin's data were 0.96 (coefficient alpha) and .94 (split-half reliability), with item-to-total corre lations ranging from 0.39 to 0.81 . All items successfully discriminated between depressed and non -depressed groups. These results suggested that the scale can be represented by a single factor.

Using samples from Turkey, Sahin and Sahin (1992) found five interpretable factors labeled negative self-concept, confusion and escape fantasies, personal maladjustment and desire for change, Ioneliness/isolation and giving up/ helplessness. These factors accounted for $57 \%$ of the total variance in the scale, but the first factor accounted for $35.1 \%$ of the variance, whereas each of the other four factors accounted for $3.9 \%$ to $5.9 \%$ of the va- 
riance. Coefficient alpha for scores on the 30item ATQ score was 0.93, split half reliability was 0.91, and item-to-total correlations ranged from 0.35 to 0.69 . Furthermore, all items successfully discriminated between depressed and non-depressed groups.

Joseph (1994) initially found six factors with eigen values greater than one for the ATQ, but the screen plot indicated a marked drop between the first and second factor. A two-factor solution was estimated and deemed the most interpretable. The first factor accounted for $38.4 \%$ of the variance, whereas the second factor accounted for only $5.6 \%$. The factors were labeled Negative SelfConcept/ Expectations and Personal Maladjustment/ Desire for Change. Coefficient alpha for scores on the ATQ was 0.94 .

Bryant and Baxter (1997) used 304 college students in a confirmatory factor analytic study. They found marginal levels of fit for the four-factor solution originally identified by Hollon and Kendall (1980). They also found that the correlations among the four factors had a median value of 0.87 and that a single dominant second-order factor underlined the 30-item ATQ. Three conclusions can be drawn from these studies. Firstly, although most studies have found more than one factor, all studies showed that a single substantive factor likely underlined the 30 items of the ATQ. Secondly, most studies indicated that some variations of the original four factors were identified by Hollon and Kendall (1980) do exist (i.e., personal maladjustment/ desire for change, negative self-Concept/ negative expectation, low self-esteem, giving up/ helplessness), but the replication of items to those factors across the studies is extremely mixed. Thirdly, regardless of the number of factors found, all studies have summed the scores on the 30 ATQ items, utilizing the scale as if it were represented by a single factor or dimension. Therefore, we sought to derive shortened forms of the scale in which one substantive factor (dimension) underlined the data, while also retaining items that reflect the content domain of the factors originally identified by Hollon and Kendall (1980).

Finally, Aldahadha (2011) investigated the relationship between automatic thoughts (AT) and neurotic behaviors (NB) among a sample of Nizwa University students, in light of some variables. The study sample consisted of (329) students. The results showed a significant positive relationship between (AT) and (NB) and some factors of (NB). According to the study, the relation was found in favor of anxiety, depression, hysteria, phobia and total scale. In regards to cumulative average, the results showed a significant relationship in favor of academic excellence and total scale, while there was a correlation between all factors of (NB) and (AT) among students of Arts except hysteria. Lastly, there was a negative relationship between the numbers of students who had access to the internet and the factor of phobia. This means that the more access to the internet the students have, the less fear of phobia they have.

\section{Limitations}

For many students who are at the stage of studying in college, their unconscious thoughts determine a variety of these behaviors. The students think, behave and feel without knowing the content of their actions, they learn to respond to events automatically, without thinking about them. As a result, the first step in the counseling process is to discover the common and extreme irrational beliefs, which can include negative and harmful thoughts. According to our experience in the field of counseling, we found, that in most stressful and dysfunctional cases, the person's style of thinking which consists of his/ her automatic thoughts are perceived as the primary reason for their stressful and dysfunctional behavior.

It is the researcher's intention to clarify the relationship between automatic thoughts and depression, and attempt to answer questions regarding automatic thoughts questionnaire and their relation to gender, college, level of study, achievement and hours of internetusage, among University of Nizwa students in Oman. The justification behind this study is to increase knowledge, awareness and descriptions about the nature of the relationship between automatic thoughts questionnaire and depression, and to provide a guideline for possible preventions and treatments for students who disrupt their academic and personal lives by negative thinking.

The following are the limitations of this study:

1- These results should be interpreted with caution due to missing information in the 
Beck Depression Inventory (BDI) questionnaire.

2- Since this study concerns only University of Nizwa students, the results cannot be generalized to all students in Oman.

3- The present study is limited to the first semester of the academic year 2010/ 2011.

\section{Significance of the study}

The study of automatic thoughts for university students is important for students themselves, faculty members, and school counselors in Oman. Findings of this research will enable educators, counselors, parents and students to determine the side effects of the negative automatic thoughts, in adequately preparing students to dispute their irrational beliefs for rational and positive ones. These beliefs will therefore benefit the students by creating the experience of positive learning and thinking in classrooms and university extracurricular activities.

Counselors and instructors may benefit from the results of this study, by helping students to identify and overcome their problems. Moreover, the results of this study may be used to guide professional university counselors to attain better counseling skills. Counselors need to continuously raise awareness, assess and dispute the negative automatic thoughts of their students. This is an indication of the effectiveness of the university counseling services. In addition, the results of this study provide us with sufficient information to arrange effective workshops to treat students suffering from negative automatic thoughts.

\section{Research questions}

The present study answers the following questions:

1. What are the most influential automatic thoughts among University of $\mathrm{Niz-}$ wa students?

2. Is there a significant relationship between automatic thoughts questionnaire and depression?

3. Is there a significant effect for gender, specialization, level of study, achievement and hours of internetusage on automatic thoughts?

\section{Population and sample}

The target population for this study consisted of all University of Nizwa students ( $\mathrm{N}=5540$ ). The sample for this study comprised (329) students in all academic levels of study at academic year 2010/2011. Total of (329) usable instruments were returned with a re sponse rate of $100 \%$. The sample gender distribution was (101) males (30.7\%) and (228) females (69.3\%).

\section{Assessment measures}

Beck D epression Inventory-second edition.(BDI-II). The 21 items of the (BDI-II) are designed to assess the severity of the affective, cognitive, motivational, psychomotor and vegetative components of depression. Alpha reliability coefficients of the BDI have been found to exceed .90 in a range of populations. The 21 items of the BDI-II can also be separated into two subscales: a cognitive-affective subscale (the sum of the first 13 items) and a somaticperformance subscale. These subscales, as well as the Total score of the BDI-II, were used in the analyses of the current study. Finally, in accordance with guidelines stipulated by Beck, Steer and Garbin (1993), the cut-offs for assessing different levels of depression were as follows: 0-9 minimal depression, 10-16 mild depression, 17-29 moderate depression; and 3036 severe depression. In the evidence prevalent in many studies that were conducted in Oman and the Arab World (BDI-II) eleven was the cut point between normal and depressed, after achieving the accredited standards of psychometric properties. This also included the accepted average of reliability and validity. Reliability measures for the depressed cases reveal ed a coefficient alpha of $0.94(p<.001)$ and a split-half coefficient of .91 ( $p<.001)$.

A utomatic Thoughts Q uestionnaire ATQ (Hollon and Kendall, 1980). This measure is a 30-item inventory in which clients are asked to indicate, on a scale of 1 (not at all) to 5 (all the time) how frequently automatic thought (negative) such as "I'm worthless" have occurred in the past week. The responding range in the questionnaire begins from 30 up to 150.

\section{Instrument translation process}

Five translators (foreign language department) bilingual in English and Arabic translated the English version of the ATQ into Arabic. These translators were instructed to 
retain both the form (language) and the meaning of the items, and to preserve them to the original as much as possible, but to give priority to meaning equivalence. When the Arabic translation was finalized, the ATQ was then back-translated (from Arabic to English) by four other department members, bilingual in English and Arabic. The back-translated items were then evaluated by a group of five faculty members to ensure that the item meanings were equivalent between the original English version and the back-translated version. The differences found between items, were re entered into the forward and back-translation process, until the evaluators were satisfied there was substantial meaning equivalence.

The Arabic version of the ATQ was then pilot tested with a group of 10 faculty members to collect feedback about the content and usage of the instrument. The feedback from the faculty members emphasized that the instrument has both face and content validity.

Factor analysis was carried out on the $30-$ item ATQ $(\mathrm{N}=329)$. Table 1 shows the factor loadings of the ATQ Items using the exploratory factor analysis (varimax rotation).
The results of Table 2 shows that there were five factors, loading above .30 and were accepted as the criterion for inclusion of an item into a factor. The five factors were named "Negative Self Concept," "Confusion/ Escape Fantasies," "Personal Maladjustment and Desire for Change," "Loneliness/Isolation," and "Giving up and Helplessness". These results are consistent with the studies of Sahin and Sahin (1992) who found that factor analysis reveal ed five factors that were similar to those found in American samples (Hollon and Kendall, 1980). The internal consistency of the instrument was determined using the same group of participants used in the pilot study.

The calculated coefficient alpha reliability for the ATQ was 0.89. The standards for instrument reliability for Cronbach's alpha by Robinson, Shaver, and Wrightsman (1991) were used to judge the quality of the scales of the instrument. These standards were: 0.84 to 1.00 - exemplary reliability, 0.73 to 0.84 - extensive reliability, 0.63 to 0.65 - moderate reliability, and $<0.63-$ minimal reliability. Based on

Table 1

Factor Loadings of the ATQ Items

\begin{tabular}{|c|c|c|c|c|c|}
\hline \multicolumn{6}{|c|}{ Factor Loadings of the A IQ I tems } \\
\hline Factors and items & 1 & 2 & 3 & 4 & 5 \\
\hline \multicolumn{6}{|c|}{ Negative Self-concept } \\
\hline 2 & 0.43 & & & & \\
\hline 3 & 0.56 & & & & \\
\hline 7 & 0.52 & & & & \\
\hline 8 & 0.38 & & & & \\
\hline 17 & 0.59 & & & & \\
\hline 18 & 0.60 & & & & \\
\hline 21 & 0.39 & & & & \\
\hline 23 & 0.67 & & & & \\
\hline 24 & 0.53 & & & & \\
\hline \multicolumn{6}{|c|}{ Confusion and Escape Fantasies } \\
\hline 13 & & 0.35 & & & \\
\hline 14 & & 0.48 & & & \\
\hline 15 & & 0.40 & & & \\
\hline 19 & & 0.55 & & & \\
\hline 20 & & 0.63 & & & \\
\hline \multicolumn{6}{|c|}{ Personal Maladjustment and Desire } \\
\hline 9 & & & 0.61 & & \\
\hline 26 & & & 0.59 & & \\
\hline 29 & & & 0.36 & & \\
\hline \multicolumn{6}{|l|}{ Loneliness/ Isolation } \\
\hline 1 & & & & 0.49 & \\
\hline 4 & & & & 0.41 & \\
\hline 10 & & & & 0.40 & \\
\hline 28 & & & & 0.59 & \\
\hline \multicolumn{6}{|c|}{ Giving up/ Hel plessness } \\
\hline 6 & & & & & 0.38 \\
\hline 11 & & & & & 0.45 \\
\hline 12 & & & & & 0.42 \\
\hline 25 & & & & & 0.40 \\
\hline
\end{tabular}


the above guidelines, the ATQ exhibited exemplary reliability, suggesting that the instrument is suitable to measure the construct understudy. The responding range on the questionnaire begins from 30 to 150.

The following steps involve the administering of both the Arabic and the English forms of ATQ to 42 senior students in the English Department. These students speak both languages fluently. The order effect was controlled by initially giving the English ATQ to half of the group and the Arabic ATQ to the other half. The correlation betwen these two forms was found to ber $=0.91$.

\section{Variables of the study}

The study consists of the following variables:

\section{- The independent variables:}

- Gender (male and female).

- Specialization (Arts and Sciences). o Level of study (first, second, third, fourth and fifth).

- Achievement (good and below, very good and excellent).

- Hours of Internet- usage (normal, moderate and addicted).

\section{- The dependent variable:}

- The automatic thoughts questionnaire scores.

- Beck Depression Inventory-second edition scores.

\section{RESULTS AND DISCUSSION}

\section{Results related to the first question}

The most influential automatic thoughts among University of Nizwa students are determined by the means of items. Table 2 shows the mean scores, standard deviation and the rank for all items of the ATQ questionnaire.

Table 2

The M ean Scores, Standard Deviation and the Rank for All Items of The ATQ Q uestionnaire

\begin{tabular}{|c|c|c|c|c|}
\hline Rank & No & Items & Mean & SD \\
\hline 1 & 7 & I wish I were a better person. & 4.26 & 1.22 \\
\hline 2 & 26 & Something has to change. & 3.63 & 1.32 \\
\hline 3 & 15 & I wish I were somewhere else. & 3.16 & 1.44 \\
\hline 4 & 27 & There must be something wrong with me. & 3.14 & 1.40 \\
\hline 5 & 9 & My life's not going the way I want it to. & 2.92 & 1.31 \\
\hline 6 & 16 & I can't get things together. & 2.90 & 1.21 \\
\hline 7 & 4 & No one understands me. & 2.89 & 1.28 \\
\hline 8 & 6 & I don't think I can go on. & 2.82 & 1.28 \\
\hline 9 & 1 & I feel like l'm up against the world. & 2.80 & 1.15 \\
\hline 10 & 14 & What's wrong with me? & 2.74 & 1.29 \\
\hline 11 & 3 & Why can't I ever succeed? & 2.55 & 1.11 \\
\hline 12 & 11 & Nothing feels good anymore. & 2.54 & 1.22 \\
\hline 13 & 20 & What's the matter with me? & 2.53 & 1.34 \\
\hline 14 & 10 & I'm so disappointed in myself. & 2.53 & 1.26 \\
\hline 15 & 21 & I'm a loser. & 2.49 & 1.25 \\
\hline 16 & 12 & I can't stand this anymore. & 2.48 & 1.25 \\
\hline 17 & 2 & I'm no good. & 2.45 & 1.19 \\
\hline 18 & 29 & It's just not worth it. & 2.42 & 1.33 \\
\hline 19 & 13 & I can't get started. & 2.33 & 1.07 \\
\hline 20 & 25 & I feel so hel pless. & 2.31 & 1.18 \\
\hline 21 & 24 & I'll never make it. & 2.28 & 1.24 \\
\hline 22 & 30 & I can't finish anything. & 2.27 & 1.23 \\
\hline 23 & 8 & I'm so weak. & 2.21 & 1.13 \\
\hline 24 & 22 & My life is a mess. & 2.17 & 1.30 \\
\hline 25 & 28 & My future is bleak. & 2.10 & 1.22 \\
\hline
\end{tabular}


Table 2

The M ean Scores, Standard Deviation and the Rank for All Items of The ATQ Q uestionnaire

\begin{tabular}{cclcc}
\hline Rank & No & \multicolumn{1}{c}{ Items } & Mean & SD \\
\hline 26 & 19 & I wish I could just disappear. & 2.05 & 1.30 \\
27 & 5 & I've let people down. & 1.91 & 1.16 \\
28 & 17 & I hate myself. & 1.87 & 1.11 \\
29 & 23 & I'm a failure. & 1.85 & 1.13 \\
30 & 18 & I'm worthless. & 1.79 & 1.13 \\
Total & & & 2.55 & 0.71
\end{tabular}

It can be noted from Table 2 that the highest five mean scores are for the items entitled " I wish I were a better person", "Something has to change", "I wish I were somewhere else", "There must be something wrong with me" and "My life's not going the way I want it to". The findings of the present study from Table 2 revealed that the lowest five mean scores are for the items entitled "I'm worthless", "I'm a failure", "I hate myself", "I've let people down" and "I wish I could just disappear".

\section{Results related to the second question}

The second question investigates whether or not there is a significant relationship be tween automatic thoughts and depression. The subjects were categorized as "non-depressed" $(\mathrm{BDI}-\mathrm{II}<10)$ and "depressed" (BDI-II> 17). These two categories were found to be appropriate in reference to Omani culture (AI- Ansari and Kathem, 2007). These groups were named "asymptomatic" and "symptomatic" as suggested by Beck, Steer, and Garbin (1988). Scores on the ATQ ranged from 30 to 150: scores for depressed people usually range from 90-130 and between 40-60 for nondepressed people (DeRubeis et al., 1990). To answer this question, Pearson correlation coefficients was utilized. The results showed that there was a positive significant correlation between automatic thought and depression $(r=$ $0.81, p<0.001$ ). Also, there was a negative correlation for non-depressed students between ATQ and depression ( $r=-0.78, p<0.001)$. This means that whenever the level of

depression is high there is also a high level of ATQ and vice versa.

As the results of this preliminary study suggest, ATQ was positively and strongly associated with BDI-II scores both in depressed and non-depressed students. Thus, this suggests that ATQ is sensitive to variations in severity of depression among normal samples as well as abnormal samples. Therefore, the ATQ could discriminate betwen depressed and non-depressed students (among students of University of Nizwa). Thus, we can depend on these results to diagnose, counsel and help students to overcome their academic obstacles, by helping depressed students discover the content of ATQ items and substantially deal with them. This finding is consistent with a previous study that found a strong correlation between ATQ and BDI-II, in a sample of nonpatient college students (Ghassemzadeh et al., 2006).

Hollon and colleagues (1986) reported a similarly strong correlation between ATQ and BDI in a mixed patient and non-patient sample. The findings from this study support the cross-cultural utility and validity of the ATQ as a measure of depressive automatic thoughts. These thoughts appear to be a consistent feature of depression which is evident across different cultures (Charles et al., 1989; Sharifi, Mojtabai, and Ghassemzadeh, 2008; Sahin and Sahin, 1992). Findings from these studies, and the present one lend some support to the utility of cognitive formulations of depression in Arab world settings, although other aspects of these formulations need to be explored in future studies. However, the findings of this study should be interpreted in the context of its previous limitations.

\section{Results related to the third question}

The third question purports to test if there is a significant effect for gender, specialization, level of study, achievement and hours of internet-usage automatic thoughts. Table 2 shows that the means and standard deviations of the students' response form accordingly to their gender, specialization, level of study, achievement and hours of internet-usage.

Table 3 shows the means and standard deviations of the students' responses on each level on the ATQ according to their gender, 
specialization, level of study, achievement and hours of internet-usage. In order to determine the effects of gender, specialization, level of study, achievement and hours of internetusage on the automatic thoughts, a t- test and one-way ANOVA were carried out. Table 4 shows the effect of gender, specialization, level of study, achievement and hours of internetusage on the automatic thoughts.

Table 4 shows that gender, specialization, level of study and hours of internet-usage had no significant effect on ATQ. On the other hand, achievement had a significant effect only on ATQ.

Although men and women are also likely to differ in how they think about different events, the two genders didn't significantly differ on ATQ.
They select different ways of responding to depression, and other obstacles when they occur. In general, men appear more likely to inhibit their automatic thoughts through distraction methods such as playing sports, engaging in hobbies and socializing with others.Conversely, women use more emotionally focused methods of coping such as seeking social support, dwelling on the causes and implications of their negative thoughts, and crying. For this reason, men seek to dispute their irrational thoughts more effectively than women do. In spite of the culture in Oman and in the Arab world, women are generally granted the same legal rights and opportunities as men are given, these include prospects of attaining equal education, work and pay. In order to identify the differences between the

Table 3

The M ean Scores and Standard Deviations of the Students' Responses on Each Level on the ATQ According to their G ender, Specialization, Level of Study, A chievement and H ours of Internet-U sage

\begin{tabular}{llccc}
\hline Variable & Level & N & Mean & SD \\
\hline Gender & Male & 101 & 2.44 & 0.78 \\
& Female & 228 & 2.59 & 0.67 \\
Specialization & Total & 329 & 2.55 & 0.71 \\
& Arts & 201 & 2.56 & 0.69 \\
Level of study & Scientific & 128 & 2.53 & 0.74 \\
& Total & 329 & 2.55 & 0.71 \\
& First & 55 & 2.54 & 0.66 \\
& Second & 92 & 2.57 & 0.58 \\
Achievement & Third & 74 & 2.61 & 0.80 \\
& Fourth & 66 & 2.37 & 0.78 \\
& Fifth & 42 & 2.68 & 0.73 \\
& Total & 329 & 2.55 & 0.71 \\
Hours of internet-usage & Good & 121 & 2.52 & 1.22 \\
& Very good & 122 & 2.86 & 1.27 \\
& Excellent & 86 & 3.24 & 1.27 \\
& Total & 329 & 2.84 & 1.28 \\
& Normal & 224 & 2.58 & 0.69 \\
& Moderate & 81 & 2.45 & 0.77 \\
& Addicted & 24 & 2.57 & 0.69 \\
& Total & 329 & 2.55 & 0.71 \\
\hline
\end{tabular}

Table 4

The Effect of G ender, Specialization, Level of Study, A chievement and H ours of Internet-U sage on the A utomatic Thoughts

\begin{tabular}{|c|c|c|c|c|c|c|}
\hline Variables & Level & $\mathrm{N}$ & $\mathrm{M}$ & SD & $\mathrm{T}$ & Sig. \\
\hline \multirow[t]{2}{*}{ Gender } & Male & 101 & 2.446 & 0.785 & $1.786^{*}$ & 0.006 \\
\hline & Female & 228 & 2.598 & 0.673 & & \\
\hline \multirow[t]{2}{*}{ Specialization } & Arts & 201 & 2.560 & 0.692 & 0.272 & 0.155 \\
\hline & Science & 128 & 2.538 & 0.745 & & \\
\hline \multirow[t]{3}{*}{ Level of study } & Between Groups & 2.975 & 4 & 0.744 & 1.476 & 0.209 \\
\hline & Within Groups & 163.256 & 324 & 0.504 & & \\
\hline & Total & 166.231 & 328 & & & \\
\hline \multirow[t]{3}{*}{ Achievement } & Between Groups & 13.799 & 2 & 6.90 & $14.756^{\text {*k }}$ & 0.000 \\
\hline & Within Groups & 152.432 & 326 & 0.468 & & \\
\hline & Total & 166.231 & 328 & & & \\
\hline \multirow[t]{3}{*}{ Hours of internet-usage } & Between Groups & 1.036 & 2 & 0.518 & 1.022 & 0.361 \\
\hline & Within Groups & 165.195 & 326 & 0.507 & & \\
\hline & Total & 166.231 & 328 & & & \\
\hline
\end{tabular}

$* p<0.05 * * p<0.001$ 
three levels of achievement, a Scheffe test was used. The results of the multiple comparisons analysis are shown in the Table 5

In regards to achievement, Table 5 shows that the mean difference is significant $(p<$ 0.05 ); Statistically significant differences exist due to the achievement variables between good GPA students and excellent GPA students, in favor of excellent GPA students. Whence discussing these results, we can assume that students with a more negative cognition or automatic thought set in relation to their achievement (successes or failures), were more likely to hold beliefs that related to anxious thoughts, over -concern and problem avoidance. In addition, they more strongly maintain that one should be thoroughly competent in all respects (High Self-Expectations) and that people who behave badly are awful and should be punished severely (Blame proneness). These data are consistent with Beck, (1995); and Beck, Rush, Shaw, and Emery, (1979) the proposition that dysfunctional beliefs or assumptions are associated with a negative cognitive set. Depending on these assumptions we can say that a student who has an excellent GPA will think negatively, because the student will exaggerate, generalize, personalize and disapprove most of the activating events around him/ her, especially the issues regarding achievement.

Based on these results can be used to present our recommendations can be made:

1. The positive relationship between negative automatic thoughts and depression indicated that the automatic thoughts are the cause of depressive symptoms; they are also the key to overcoming depression. Therefore it is important to measure the level of depression through analyzing the content of negative automatic thoughts.

2. Counselors and psychotherapists can benefit mostly from these results by spreading counseling awareness about the harmfulness of negative automatic thoughts on depression. This is done through lectures, workshops, training courses, developmental programs, out- reach pangrams, individual counseling and group counseling.

3 . College counselors in students counseling centers must provide students with aware ness about automatic thoughts, especially students with excellent GPA, as by becoming aware of their automatic thoughts, the students will become able to systematically diagnosis their feelings toward themselves, others and the future, in order to correct their cognitive errors.

Counselors and psychotherapists must provide special counseling services for female students, by encouraging them to participate in advanced workshops which teach them how to dispute the negative thoughts beyond their misery and stress.

4. We would suggest that the researchers in this field conduct more studies on the effectiveness of group counseling or individual counseling to reduce negative automatic thoughts.

5. Finally, future studies need to assess the ability of ATQ to discriminate depressed patients from other psychiatric patients.

\section{REFERENCES}

Al-Ansari, B. \& Kathem, A. (2007). The differences between anxiety and depression among both of Sultan Qaboos University students and Al- Kuait University students. Journal of Psychological and Studies Research Center, 3(1), 221-133.

Aldahadha, B. (2011). The automatic thoughts and its relationship with 20 eurotic responses, among a sample of University of Nizwa students, in light of some variables.

Table 5

Scheffe Post H oc Test of M ultiple Comparison A ccording to A chievement Levels

\begin{tabular}{llccc}
\hline \multicolumn{2}{c}{ Independent variable (achievement) } & Mean Difference (1-2) & Std. Error & Sig. \\
\hline Achievement (1) & Achievement (2) & & & \\
\hline Good & Very good & 0.024 & 0.088 & 0.962 \\
\multirow{2}{*}{ Very good } & Excellent & $0.478^{*}$ & 0.096 & 0.000 \\
& Good & -0.024 & 0.088 & 0.962 \\
Excellent & Excellent & $0.453^{*}$ & 0.096 & 0.000 \\
& Good & $-0.478^{*}$ & 0.096 & 0.000 \\
& Very good & $-0.453^{*}$ & 0.096 & 0.000 \\
\hline
\end{tabular}


Journal of the Gulf and A rabian Peninsula Studies. Educational Sciences.

Beck, A. T., Steer, R. A., \& Garbin, M. G. (1988). Psychometric properties of the Beck Depression Inventory: Twenty-five years of evaluation. Clinical Psychology Review, 8, 77100.

Beck, A. T., Rush, A. J., Shaw, B. F., \& Emery, G. (1979).Cognitive therapy of depression. New York: Guilford Press.

Beck, A. T. (1995).Cognitive therapy: Basic and beyond. New York: Guilford Press.

Beck, A. T. (1996). Beyond belief: A therapy of modes, personality, and psychopathology. New York: Guilford press.

Boelen, P. A., (2007). Psychometric properties of the Dutch version of the automatic thoughts questionnaire-positive (ATQ-P). Cognitive Behavior Therapy, 36(1), 23-33.

Bryant, F. B. \& Baxter, W. J. (1997). The structure of positive and negative automatic cognition. Cognition and Emotion Journal, 11, $225-258$

Charles, S., Mollard E., \& Cottraux J. (1989). Validation and factorial structure of the French version of the Automatic Thoughts Questionnaire. Poster presented at the World Congress of Cognitive Therapy, Oxford, UK.

Clark, D. A. (1988). The validity of measures of cognition: A review of the literature. Cognitive Therapy and Research, 12, 1-20.

Clark, L. A. \& Watson, D. (1991). Tripartite model of anxiety and depression: Psychometric evidence and taxonomic implications. J ournal of A bnormal Psychology, 100, 316-336.

Deardorff, P. A., Mcintosh, J. A., A damek, C. A., Bier, M., \& Saalfeld, S. (1985). A utomatic Thoughts Questionnaire: A study of concurrent validity. Psychological Reports, 57, 831834.

DeRubeis, R. J., Evans, M. D., Hollon, S. D., Garvey, M. J., Grove, W. M., \& Tuason, V. B. (1990). How does cognitive therapy work? Cognitive change and symptoms change in cognitive therapy and pharmacotherapy for depression. Journal of Consulting and Clinical Psychology, 58(6), 862-869.

Dobson, K. S., \& Show, B. F. (1986).Cognitive assessment with major depressive disorders. Cognitive Therapy and Research, 10, 13-29.

Dowd, E. T. (2003). Depression: Theory assessment, and new directions in practice International. Journal of Clinical and $\mathrm{H}$ ealth Psychology, 4(2), 413-423.

Ghossemzadeh, H., M ojtabai, R., Karamghadiri, N. \& Ebrahimkhani, N. (2006). Psychometric properties of a Persian- Language Version of the automatic thoughts questionnaire: ATQ-Persian. International Journal of social Psychiatry, 52(2), 127-137.

Glass, C. R, \& Arnkoff, D. B. (1997). Questionnaire methods of cognitive self-statement assessment. Journal of Consulting and Clinical Psychology, 65, 911-927.

Harrell, T. H., \& Ryon, N. B (1983). Cognitivebehavioral assessment of depression clinical validation of the Automatic Thoughts Questionnaire. Journal of Consulting and Clinical Psychology, 51, 721-725.

Hill, C. V., Oei, T. P. \& Hill, M. A. (1989). An empirical investigation of the specificity and sensitivity of the automatic thoughts questionnaire and the dysfunctional attitudes scale. Journal of P sychopathology and Behavioral A ssessment, 11, 291-311.

Hollon, S. D. \& Kendall, P. C. (1980). Cognitive self-statements in depression: Development of an Automatic Thoughts Questionnaire. Cognitive Therapy and Research, 9, 443-453.

Hollon, S., D., Kendall, P.C \& Lumry, A. (1986). Specificity of depression topic cognitions in clinical depression. Journal of A bnormal Psychology, 95, 52-59.

Ingram, R. E. \& Wisnicki, K. S. (1988). Assessment of positive automatic cognition. Journal of Consulting and Clinical Psychology, 56, 898902.

Joseph, S. (1994). Subscales of the Automatic Thoughts Questionnaire. Journal of Genetic Psychology, 155(3), 367-368. 
Kazdin, A. E. (1990). Evaluation of the Automatic Thoughts Questionnaire: Negative cognitive processes and depression among children. Psychological Assessment, 48 (2)7379.

Robinson, J. P., Shaver, P. R., \& Wrightsman, L. S. (1991). Criteria for scale selection and evaluation. In J. P. Robinson, P. R. Shaver, and L. S. Wrightsman (Eds). M easures of personality and social psychological attitudes (pp. 1-6). New York: A cademic Press.

Sahin, N., H. \& Sahin, N. (1992). Reliability and validity of Turkish of the automatic thoughts questionnaire. Journal of Clinical Psychology, 48 (3), 334- 340.
Sharifi, V., Mojtabai, R., \& Ghassemzadeh, H. (2008). Use of the Persian language version of the automatic thoughts questionnaire in depressed Iranian women. Depression and Anxiety, 25, 35- 38.

Yucel, B., Kora, K. Ozyalcin, S., Alcalar, N. \& Ozdemir, O. (2002). Depression, automatic thoughts, alexithymia, and assertiveness in patients with tension-type headache, $\mathrm{H}$ eadache, 42, 194-199.

Authors' Note. This research was funded by the Central Budget of U niversity of Nizwa. 